was one of Audible.com's audiobooks of the year for 2010. While he enjoyed writing about other sciences, he still felt his portfolio was incomplete without a book about the subject he knew best. Princeton University Press will publish his first full-length popular book about mathematics, titled The Universe in Zero Words, in 2012. Mackenzie still lives in Santa Cruz with his wife, Kay, and an ever-changing array of foster animals.

\section{Response from Dana Mackenzie}

I like to tell people that my job gives me the opportunity to get free lessons from the smartest people in the country every week. For someone who likes learning new things, journalism- especially science journalism-is like a never-ending trip to the candy store. I never know what I'm going to turn up next.

Winning the JPBM Communications Award evokes two predictable emotions, which are both sincere in spite of their predictability. First, I am humbled by the list of previous winners. I see names of people who inspired me, such as Martin Gardner, Constance Reid, Ian Stewart, and Sylvia Nasar. I also see people like last year's winners, Nicolas Falacci and Cheryl Heuton, who have done much more than I ever could to bring mathematics to the masses.

The second sincere emotion is gratitude. I would like to thank several people, some well known and others not, without whom this journey would never have happened. Barry Cipra helped me get started in the writing business. Editors like Robert Coontz at Science and Brian Hayes and Rosalind Reid at American Scientist taught me the craft. John Wilkes had the vision to start the Science Communication Program at UCSC and gave me the last slot in the class of 1997, when I barely applied before the deadline. Ed Dunne and Jim Maxwell at the American Mathematical Society entrusted me with the What's Happening in the Mathematical Sciences series, so well begun by Barry Cipra. And Martin Gardner and George Pólya, neither of whom I ever met, were my greatest inspirations.

- Elaine Kehoe

\title{
MAA Prizes Presented in Boston
}

At the Joint Mathematics Meetings in Boston, Massachusetts, in January 2012, the Mathematical Association of America (MAA) presented several prizes.

\section{Gung and Hu Award for Distinguished Service}

The Yueh-Gin Gung and Dr. Charles Y. Hu Award for Distinguished Service to Mathematics is the most prestigious award made by the MAA. It honors distinguished contributions to mathematics and mathematical education, in one particular aspect or many, whether in a short period or over a career.

The 2012 Gung and $\mathrm{Hu}$ Award was presented to JoHN EwING, president of Math for America.

John Ewing received his Ph.D. in mathematics from Brown University in 1971 and, after a twoyear postdoctoral appointment at Dartmouth, he joined the mathematics department faculty at Indiana University. He quickly became known on campus not only as a very good teacher and researcher but also as a team player and leader who

Elaine Kehoe is contributing writer for the Notices. Her email address is e1aine1kehoe@cox. net.

DOI: http://dx.doi.org/10.1090/noti843 worked to improve the department, the campus, and the field of mathematics. At Indiana, he began his administrative career as director of undergraduate studies (1978-1980) and later served as chair of the mathematics department (1986-1989 and 1992-1995). During this period, while serving as the editor of the Monthly and the editor of Graduate Texts at Springer-Verlag, he played a key role in the expansion of the department, the renovation of two department buildings, and the strengthening of the department in both teaching and research. Also, while at Indiana, he published approximately thirty-five research papers in algebraic topology and related areas, supervised three Ph.D. students, and held visiting positions at the University of Virginia, Newcastle University, and the University of Göttingen.

Outside of Indiana University, Ewing first turned his considerable administrative skills to publication. In addition to work on editorial boards too numerous to list, he served as editor of the American Mathematical Monthly (1992-1996) and of the Mathematical Intelligencer (1980-1986). While he was editor, these journals were distinguished by articles containing engaging, accessible, and important mathematics. In 1994 Ewing edited the MAA publication A Century of Mathematics: Through the Eyes of the Monthly. Underwood 
Dudley's review in the Intelligencer captures Ewing's editorial style: "This is a rich and fascinating book. It has everything, and everything that it has is delightful, curious, enlightening, engrossing, interesting, informative, funny, stirring, poignant, or some combination of the preceding."

Between 1995 and 2009 Ewing served as executive director of the American Mathematical Society. His decisions within the AMS were always guided by a commitment to serve not only the specific interests of the AMS but also those of the broader mathematical sciences community. He is very much a "big tent" mathematician, always maintaining strong and cordial working relationships with his professional society colleagues, especially at the MAA and SIAM. New joint projects of the time that benefited from the mutual cooperation of the mathematics organizations included public awareness activities and government outreach.

As an example of his big tent vision, in Science in 1997, he called attention to the importance of Project NExT: "By bringing young mathematicians to meetings several years in a row, you show them the value of contacts. Most young mathematicians learn that slowly, over many years, or never learn it at all. Project NExT fellows have it handed to them for free." In 2001 the AMS began funding six Project NExT fellows per year.

In 1999 an AMS task force produced the influential and no-holds-barred Towards Excellence: Leading a Mathematics Department in the 21st Century, which was edited by Ewing and is available at no cost on the Internet. This volume quotes deans who report that mathematics departments tend to be too insular, and it emphasizes the importance of mathematics departments building good relationships with other departments across campus. The MAA's Guidelines for Programs and Departments in Undergraduate Mathematical Sciences calls Towards Excellence "an excellent reference for a planning and evaluation process" and David Bressoud, past president of the MAA, calls it "one of the most useful resources for making the case for greater support for curricular and instructional improvement." In 2002 Ewing presented the ideas in Towards Excellence at an MAA PREP workshop, Leading the Academic Department: A Workshop for Chairs of Mathematical Science Departments.

Ewing is a recognized expert in scholarly publishing and has been a strong, articulate, balanced, and visible voice about the role of professional society publishers in working for the long-term survivability of peer-reviewed journals as an essential tool for research and scholarship. He spoke eloquently, effectively, and sensibly at national and international venues on the issues that surround scholarly publishing, especially nonprofit publishers, and wrote an important series of commentaries on the state of publishing in the mathematical sciences. While he has not been an advocate of totally free access, which he finds unsustainable, he has worked tirelessly to improve access to the mathematical literature. He has been committed to low-cost, high-quality electronic publishing, with author-friendly copyright policies, and to databases that make an exhaustive literature search possible. The Digital Mathematics Registry, which went online in 2006, is a complete list of digitized publications in the mathematical sciences. The AMS maintains this registry as a public service, which is, itself, in the public domain. Mathematical Reviews, online through MathSciNet since 1996, is one of the indispensable tools of the working mathematician. Ewing's contributions to the growth and enhancement of Mathematical Reviews were substantial. With the advice of the senior MR staff and oversight committees, he worked first and foremost setting the agenda for improvements to the database. He is a detail-oriented person, and so his role was rather direct. He is very knowledgeable on the role of technology in building and serving information. He instituted a pricing scheme with the result that the number of institutions that could subscribe to MR doubled in a decade. He arranged for all reviews back to the first issue in 1940 to be digitized. There is no doubt that he was key to moving the project forward to produce the MR tools and database that we have today. Ewing chaired the Joint IMU/ICIAM/IMS Committee on Quantitative Assessment of Research Citation Statistics. Their report, a critical analysis of the use and misuse of citation statistics in science, was published as the lead article in Statistical Science in 2009. The report was featured in the Wall Street Journal and on MathDL.

In 2009 Ewing became president of Math for America. The mission of the nonprofit Math for America is "to improve mathematics education in U.S. public secondary schools by recruiting, training, and retaining outstanding mathematics teachers." When he became president, he said, "After three years, roughly forty percent of the teachers of mathematics [in U.S. schools] are gone.... You can't sustain a profession if you have that kind of attrition.... What Math for America does is concentrate on that one part of the problem. At the moment, it's bringing through something like forty to fifty new teachers a year. Our hope is to double that number in the next couple of years" (Science, January 2009). Since Ewing became president, Math for America has enlarged to about 420 participants, expanded to new cities, and developed new programs, including one for science teachers. Recently, he has again served on several MAA committees, including the Pólya Lecturer Committee and as chair of the 2010 search committee for the editor of the Monthly.

He has received the following awards: the Lester R. Ford Award (1975); SERC, Great Britain, Research Fellowship (1981); SFB Fellowship, Federal Republic 
of Germany (Göttingen) (1984); the MAA George Pólya Lectureship (1991-1992; 1992-1993); Honorary Doctorate of Science, St. Lawrence University (1995); the George Pólya Award (1996); Fellow, American Association for the Advancement of Science (2005).

Throughout his career, John Ewing has been an effective and firm, but gentle, leader. As Jonathan Borwein, a former MAA governor, wrote about serving with Ewing on the Committee on Electronic Information and Communication (CEIC) of the International Mathematical Union, "John is an enormously hard-working man-this is not a secret-who wears his remarkable erudition and breadth of knowledge very lightly. He is patient, hard to ruffle, and even harder to alienate. The CEIC was formed with many passionate members, all knowledgeable about some bits of the puzzle. It had only one expert: John Ewing. John's patience and generosity in educating the rest of us about the many pitfalls and subtleties was extraordinary. His care in trying to distinguish his role as committee member from that as AMS executive director (which could have made him the eight-hundredpound gorilla on the committee) was remarkable."

\section{Chauvenet Prize}

The Chauvenet Prize recognizes a member or members of the MAA for the writing of an outstanding expository article. First awarded in 1925, the prize is named for William Chauvenet, who was a professor of mathematics at the United States Naval Academy and Washington University in St. Louis (where he founded the mathematics department).

The 2012 Chauvenet Prize has been awarded to DENNIS DETURCK and HERMAN GLUCK, both of the University of Pennsylvania; DANIEL POMERLEANO of the University of California, Berkeley; and DAVID SHEA VELA-VICK of Columbia University for their joint paper "The four vertex theorem and its converse", Notices of the American Mathematical Society 54 (2007), no. 2, 192-207. The four vertex theorem is a beautiful result in global differential geometry. It says that any smooth simple closed curve in the plane must have at least four "vertices"-local extrema for the curvature function. The vertices of a (noncircular) ellipse, for example, are located where it meets its major and minor axes. The four vertex theorem was proved for convex curves in 1909 by Syamadas Mukhopadhyaya and for general curves in 1912 by Adolf Kneser. Remarkably, the converse of the four vertex theorem is also true. Any continuous real-valued function on the circle with at least two local maxima and two local minima is the curvature function for some simple closed curve in the plane. The converse was proved for positive functions in 1971 by Herman Gluck and for arbitrary functions in 1997 by Björn Dahlberg.
The authors of this excellent expository article sketch Robert Osserman's 1985 proof of the four vertex theorem and Dahlberg's proof of the converse. The article ends with some generalizations of the four vertex theorem and biographical sketches of Mukhopadhyaya, Kneser, and Dahlberg. This carefully crafted survey has enough mathematical details to give the reader a sense of the proofs, but not so many as to obscure the big picture. Experts and nonexperts alike are sure to enjoy and understand this well-written and wellillustrated article. It is also a wonderful tribute to Björn Dahlberg, who passed away in early 1998, with his unpublished proof of the full converse still on his desk.

\section{Euler Book Prize}

The Euler Book Prize is given to the author(s) of an outstanding book about mathematics. Mathematical monographs at the undergraduate level, histories, biographies, works of mathematical fiction, and anthologies are among those types of books eligible for the prize. The prize was given for the first time in 2007, the 300th anniversary of the birth of Leonhard Euler.

DAINA TAIMIN,A of Cornell University has been awarded the 2012 Euler Book Prize for Crocheting Adventures with Hyperbolic Planes (A K Peters, Ltd., 2009).

This book is unlike any previously considered for the Euler Prize. Indeed, it is unlike any book on hyperbolic geometry previously written, and it is in a different universe from any book on crochet previously written. But, when you look at it, the idea makes such perfect sense that it seems inevitable. Eugenio Beltrami, who in 1868 first modeled the non-Euclidean geometry of Bolyai and Lobachevsky by surfaces of negative curvature, actually toyed with the idea of building such surfaces. He made a small fragment of such a surface out of paper, and the idea was taken up again by William Thurston in the 1970s. But the idea did not take off, let alone reach a wide audience, until Daina Taimiņa wrote this book. By bringing crochet technology to the subject, she makes it easy and fun to construct hyperbolic surfaces that vividly illustrate essential features of non-Euclidean geometry. The book is elegant, from both a visual and mathematical point of view.

Thus Crocheting Adventures with Hyperbolic Planes is a novel approach to geometry that has brought a whole new audience to mathematics. In this respect it has greater outreach potential than any book we have previously considered. But it is much more than that; it is perfectly capable of standing on its mathematical feet as a clear, rigorous, and beautifully illustrated introduction to hyperbolic geometry. It is truly a book where art, craft, science, and mathematics come together in perfect harmony. 


\section{Beckenbach Book Prize}

The Beckenbach Book Prize, established in 1986, is the successor to the MAA Book Prize, which was established in 1982. It is named for the late Edwin Beckenbach, a long-time leader in the publications program of the association and a well-known professor of mathematics at the University of California at Los Angeles. This prize is awarded to an author of a distinguished, innovative book published by the MAA. The award is not given on a regularly scheduled basis but is given only when a book appears that is judged to be truly outstanding.

The Beckenbach Book Prizes for 2012 were awarded to DAN KALMAN (American University) and NATHAN CARTER (Bentley University)

Kalman was honored for Uncommon Mathematical Excursions: Polynomia and Related Realms (The Dolciani Mathematical Expositions, Vol. 35, Mathematical Association of America, 2009). Just how interesting can a book be whose only topic is polynomials? It doesn't take long to find out. By page 3 in Kalman's book, we encounter Lill's ingenious paper-folding technique for visualizing real roots of a polynomial, with an elegant proof based on Horner's method to evaluate a polynomial. Now most mathematicians are vaguely aware of Horner's method, but try to find one who knows Lill's technique, or one that knows that the first mention of Lill's idea in the United States appeared in an 1879 pamphlet by a lieutenant in the Army Corps of Engineers. By Chapter 2 we find that if a cubic $p(x)$ has three noncollinear roots in the complex plane, the unique ellipse inscribed in the triangle formed by those roots has the roots of $p^{\prime}(x)$ as its foci (Marden's theorem) and that a polynomial $p(x)$ with positive integer coefficients is completely determined by the value of $p(1)=b$ and $p(b)$ (think base $b$ ). There is much, much more: palindromials, polynomial interpolation, symmetric functions, Newton's identities, and a brief history of Cardano's formula for the roots of a cubic (again, who knew Mark Kac sharpened his teeth at age fifteen on his own method of getting Cardano's formula?); and that is only the first third of the book! The next part covers max/min problems, beginning with a careful analysis of the Lagrange fallacy, then moving on to the Milkmaid problem, rotating ellipses, the ladder-around-the-corner (done with envelopes!), and the old shortest-time path through-or-around a field but with a discontinuous objective function. The last section focuses more on calculus questions, the wonder of elementary functions, and the expansion of the toolbox with special functions to solve, for example, $e^{x}=$ $c x$. The exposition is perfect: expansive, relaxed, and detailed (almost nothing is stated without being proved). Although knowledge of calculus is needed, any good undergraduate mathematics major can read the entire book, as could many talented high school students. The book is a gold mine of topics for undergraduate talks. Kalman received his Ph.D. from the University of Wisconsin, Madison. He has been a frequent contributor to all of the MAA journals and has served on the editorial boards of both MAA book series and journals. He has served the national and regional MAA in several capacities, including a term as associate executive director for programs and as the current governor for the Maryland-DC-Virginia section.

Carter was honored for Visual Group Theory (Classroom Resource Materials Series, Mathematical Association of America, Washington, D.C., 2009). Burnside's classic text Theory of Groups of Finite Order was the first book written on group theory; it begins by defining a group as a collection of operators closed under multiplication and inverses (no associative law). Groups don't just sit there, they do something, they act on something, as permutations or symmetries or isometries. This is where groups come from, and it is the standard viewpoint both of users in physics, geometry, analysis, topology, and combinatorics, and also of specialists in permutation groups, representations, and geometric group theory. Unfortunately, this viewpoint is almost absent from present undergraduate textbooks. Nathan Carter's eyeopening textbook has a mission to fix that. Using a Rubik's Cube as a motivating example, he returns to Burnside's definition, only with "actions" instead of "operators". This is followed by Cayley diagrams to show how a group looks; Dehn's term grüppenbilder, or group pictures, was always the better name. Next come motivating examples: symmetries of polygons, crystals, frieze patterns, contra dancing, roots of polynomials. Chapter 4 , entitled "Algebra at last", finishes with the "classic" definition of a group, although the action definition is really the classic one. Lastly, much of the traditional content of an undergraduate text on group theory can be found in Carter's text: the alternating and symmetric groups, abelian groups, subgroups, products and quotients, homomorphisms, Sylow theory, and a little Galois theory. The presentation is never traditional. Turn to any page and a figure jumps out: Cayley diagrams, colored multiplication tables, permutations as arrows from letter to letter-even Sylow theory is accompanied by conceptual sketches outlining the proofs. The exposition is breezy and leisurely: theorems are "taken out for a test drive," a proposition "gives us a headstart," a statement is "dense with notation" or "hairy". Steps are explained, proof strategies are analyzed-anything to loosen the seductive (after the fact) but intimidating (before the fact) concision and formality of algebra. The result is a textbook that reads like a conversation. Nathan Carter's Visual Group Theory is an original breakthrough that has a chance of transforming a staple of a mathematics major's diet. Carter received his 
Ph.D. in mathematical logic from Indiana University in 2004. He uses computer science to advance mathematics.

\section{Haimo Awards for Teaching}

The Deborah and Franklin Tepper Haimo Awards for Distinguished College or University Teaching were established in 1991. These awards honor college or university teachers who have been widely recognized as extraordinarily successful and whose teaching effectiveness has been shown to have had influence beyond their own institutions.

The 2012 Haimo Awards were presented to MATTHEW DELONG (Taylor University), SUSAN LOEPP (Williams College), and CYNTHIA WyELS (California State University, Channel Islands).

Matthew DeLong is a passionate and reflective teacher who challenges his students, from the math-anxious to the most able, to higher levels of accomplishment. His personal qualities of integrity, creativity, caring, and patience contribute to his ability to connect with students on an individual basis and encourage them to do their best work. He has also become a leader in professional development for collegiate mathematics teaching and in student-centered instruction. While a Ph.D. student at the University of Michigan, he was the first graduate student put solely in charge of a course of ten sections of precalculus, received the Rackham Pedagogy Award for materials designed to facilitate the pedagogical development of graduate student instructors, and was responsible for helping plan and run the professional development week for graduate students and postdocs. He is the 2005 recipient of the MAA's Henry L. Alder Award for Distinguished Teaching by a Beginning College or University Faculty Member. At Taylor University, DeLong started and leads the monthly School of Natural and Applied Sciences Educational Issues Seminar and is Taylor University's first Center for Teaching and Learning Excellence Fellow. He is dynamic in the classroom and implements progressive and innovative teaching strategies. A typical class session involves students presenting homework solutions, mini-lectures, and group problem-solving activities from handouts. He keeps the class moving quickly and on task, while encouraging the students to explore the "why" questions and to understand the mathematics. Students meet in groups outside of class to solve "team homework" problems, and they take turns writing the solutions to these problem sets. DeLong expects students to read the textbook before class by employing a blog for students to post questions on their reading. DeLong developed a liberal arts general education course at Taylor University that engages students in meaningful activities involving the application of mathematics skills and content as part of real-world problem solving. DeLong has published several articles on student-centered instruction and has given many regional and national professional presentations on teaching mathematics. He also coauthored the MAA book Learning to Teach and Teaching to Learn Mathematics: Resources for Professional Development (MAA Note Series, no. 57, 2001). This book presents a model for training college mathematics instructors in a collegiate program. Reviews say it "offers a treasure chest of ideas" and that this "high-quality comprehensive resource belongs in every mathematics instructor's hands." DeLong has led Taylor University's Mathematics Contest Team to a top-three finish seven times in the last ten years of the Indiana Collegiate Mathematics Competition, and he initiated an undergraduate research program at Taylor in which he has supervised students, two of whom have recently had their research published in Mathematics Magazine. In 1993 DeLong received his B.A. in mathematics and economics from Northwestern University and in 1998 he received his Ph.D. in mathematics from the University of Michigan. His mathematical interests are number theory and knot theory; other interests include faculty development, coaching little league sports, singing and conducting sacred choral music, performing and directing in musical theater, and singing in his faculty quartet, Quadrivium.

Susan Loepp has a profound influence on her students, challenging them to reach their full potential through high standards and talented encouragement. Her mentoring of a diverse group of students has inspired passion and encouraged many to major in mathematics. She also advises numerous undergraduates to successfully publish research and has created new courses and a concomitant book. She received an unprecedented three teaching awards as a graduate student at the University of Texas, Austin, and also the 2007 Alumni Award from her alma mater, Bethel College in Kansas. Her teaching evaluations at Austin, the University of Nebraska, and Williams College shine above most others. At Williams College, Loepp challenges and encourages a diverse group of students, men and notably women, athletes and scholars, the anxious and the overconfident. Loepp has high standards, assigning both daily and weekly problem sets, about which students have been known to brag how long it took and that they were able to finish. She says, "I am passionate about setting high standards for students and then helping them struggle to reach their potential." Loepp's colleagues write that she exudes energy, interest, confidence, and knowledge; "has a lively, friendly, inviting teaching style, but it's clear that she means business"; that she has the "courage to explore tough/pointless/all student questions, [even] if it [means] departing from her lesson plan"; and that she has an impressive ability to conduct class discussion: "She drew perceptive and eager 
responses from her students...due, in part, to her engaging them in vital mathematical conversation and exploration. Susan knows the importance of giving the students time to think." Loepp empowers students, connecting with them individually and inspiring mathematical zeal, encouraging many to become mathematics majors. Students are clearly infected by her enthusiasm. She also guides numerous students in undergraduate research in commutative algebra: she has seven joint papers with undergraduate students, and six additional research papers have been published by her students. She has advised thirty-two summer research students from across the country in the NSF "SMALL" undergraduate research project, and many of these have given student talks at conferences. A colleague writes, "It is remarkable that Loepp is able to make this very technical material accessible to undergraduate students. To bring students to the point of producing publishable results is truly incredible." Additionally, Loepp has advised thirty-five student colloquia at Williams College. Finally, she has created three courses that emphasize applications: a senior seminar on algebraic error-correcting codes, a course on quantum cryptography (which utilizes a book she cowrote with William $\mathrm{K}$. Wootters), and an applied version of a core requirement in abstract algebra, including encryption on elliptic curves. Loepp received a B.A. in mathematics and a B.S. in physics from Bethel College (North Newton, Kansas) in 1989. She earned her Ph.D. in mathematics from the University of Texas at Austin in 1994. Her research area is commutative algebra. She is coauthor with William K. Wootters, an expert in quantum information theory, of the book Protecting Information: From Classical Error Correction to Quantum Cryptography (Cambridge University Press, Cambridge, 2006).

Cynthia Wyels is committed to student success. She works tirelessly to facilitate student learning, not only for her own students but also for students of her colleagues, students across her university, and students at other universities, including in other countries. Her devotion to supporting learning extends to students of all backgrounds and abilities. Wyels invests considerable time, creativity, and enthusiasm in developing, employing, and assessing innovative teaching practices. One example is her development of computer laboratory activities that lead students to understand and explore key concepts in a variety of undergraduate mathematics courses. Another example is her creation of in-class worksheets that help students to concentrate on the big picture of mathematical ideas being presented. More recently, she has begun to use "proof portfolios" to track students' abilities to construct complete, correct, and elegant proofs as they progress through their undergraduate studies. Wyels has shared all of her teaching innovations with her departmental colleagues and also more broadly through various MAA conferences and publications. Providing students with enriching research experiences is a particular passion of hers. She has led Research Experience for Undergraduates programs that have emphasized participation from students in underrepresented groups, particularly native Spanish speakers and first-generation college students. She has regularly donated her own faculty stipend in order to support participation of students from a Mexican university. She has mentored sixty-three undergraduates in research, including thirty-eight from underrepresented groups, with several of these projects leading to coauthored research papers. Wyels has also led efforts to institutionalize student research on her campus and to create an annual student research symposium. Wyels's dedication to effective teaching extends across her campus, as does her commitment to providing productive learning environments for all students. She founded the Critical Friends Group at CSU, Channel Islands, which colleagues report as having fostered a cultural shift in attitudes toward teaching, especially with regard to supporting students who initially find university culture to be confusing and alienating. Students and colleagues alike attest to the tremendous influence that she has had as a mentor, not only on their study of mathematics and their careers in mathematics and education but also in developing their self-confidence, persistence to succeed, and professionalism for handling all situations. Testimonials bear witness to her high standards and meticulousness and also to her generosity, enthusiasm, kindness, and selflessness. Wyels received her Ph.D. at the University of California, Santa Barbara. She has directed the graduate program at CSU, Channel Islands, since its inception. She is an advocate of undergraduate research and believes it is particularly meaningful for students from nontraditional backgrounds. Her research interests are in combinatorics, most recently in graph pebbling and graph labeling.

\section{Certificates for Meritorious Service}

Each year the MAA presents Certificates of Meritorious Service for service at the national level or for service to a section of the MAA. Those honored in 2012 are: DAVID KERR (Eckerd College), Florida Section; JoE YANIK (Emporia State University), Kansas Section; RuTH FAVRO (Lawrence Technological University), Michigan Section; FRANK FORD (Providence College), Northeastern Section; HoRTENSIA SOTO-JOHNSON (University of Northern Colorado), Rocky Mountain Section; and MiNERVA CORDEROEPPERSON (University of Texas, Arlington), Texas Section.

- Elaine Kehoe 